\title{
Creation and Verification of Numerical Model of Explosive Charge Blast in The Ansys Software System, for the Purpose of Substantiating the Optimal Parameters of Drilling and Blasting Operations
}

\author{
Alexey Mysin ${ }^{1},{ }^{*}$, and Vladimir Kovalevskiy ${ }^{1}$ \\ ${ }^{1}$ Saint-Petersburg Mining University, 199106, 2, 21st Line, St Petersburg, Russian
}

\begin{abstract}
The purpose of this paper was to create a numerical model of explosive destruction of a rock slab by exploding a cylindrical explosive charge. The paper considers the features of solving the problem of explosive charge using the finite element method in a three-dimensional setting. The equations of state of materials used for calculations are given. The results of the laboratory experiment carried out on the basis of the laboratory: "Physical and technological processes of rock destruction" and "Physics of rock destruction by explosive energy" of the Department of Blasting works of the Mining University are presented. The comparison of the results of the laboratory experiment and the numerical modeling performed using the ANSYS software system is presented. Experimental research has shown that having clarified the constants in the polynomial equation of state of the material and the Johnson-Holmquist strength model, the results of numerical modeling, in general, are similar to the experimental ones. The obtained and verified numerical model of the cylindrical explosive charge blast is considered as the basis for choosing the optimal parameters of drilling and blasting works.
\end{abstract}

\section{Introduction}

During opencast mining one of the most important technical elements is rock defragmentation using an explosive method with subsequent loading and transportation of the rock mass outside the quarry. At the same time, the development of methods to control the effect of a blast, providing the most complete consideration of specific conditions of blasting operations, as well as the correct combination and use of factors affecting the final result of the blast, delivers a quick and cost-effective solution to a particular technological problem. The effect of a blast on a solid environment is a highly complex phenomenon. Too fast processes, very high pressure arising from the blast, as well as the impossibility to

* Corresponding author: mysin av@pers.spmi.ru 
observe directly the development of the process in opaque environments complicate the investigation of the blast $[1,2]$.

That is why it is rather difficult to predict the results of drilling and blasting operations. Trial blasts are the most indicative of determining the effect of a particular structure's charge under certain mining and geological conditions [3]. However, under conditions of continuous operation of industrial plants, it is economically inexpedient to conduct industrial experiments, so we suggest using modern means of mathematical modeling. Namely, conducting a range of laboratory experiments provided that the maximum number of similarity criteria are met. Based on these results, creating and conducting a numerical calculation of the rock sample destruction by blast [4]. In turn, a verified numerical model, including the results of experimental research, will make it possible to choose the optimal parameters of drilling and blasting operations for a particular field.

\section{Materials and methods}

The object of this paper is the quarry of Mikhailovskoye iron ore deposit. A laboratory experiment was carried out on the slabs delivered from the mentioned field. For full similarity of the processes arising in case of the blast in rocks under actual conditions, first of all, the geometrical similarity of all linear sizes with the scale equal to the relation of radii of a charge of nature and the model equivalent on the energy of the blast, and performance of kinematic and dynamic similarity is necessary. Details of the similarity scales are presented in Table 1.

Table 1. Indicators of similarity scales for a laboratory experiment.

\begin{tabular}{|c|c|c|}
\hline Indicators & Rock & Model \\
\hline $\begin{array}{c}\text { The average speed of a longitudinal wave } \\
\text { in a medium, } \mathrm{m} / \mathrm{s}\end{array}$ & 5200 & 5200 \\
\hline Charge radius, mm & 125 & 2 \\
\hline Compressive strength, MPa & 160,3 & 160,3 \\
\hline Tensile strength, MPa & 21,9 & 21,9 \\
\hline Poisson's ratio & 0,25 & 0,25 \\
\hline Young modulus, GPa & 108 & 108 \\
\hline Density, kg/m ${ }^{3}$ & 3565 & 3565 \\
\hline \multicolumn{2}{|c|}{ Similarity scales } \\
\hline Extended geometrical & 1 & 62,5 \\
\hline Velocity & 1 & 1 \\
\hline
\end{tabular}

To comply with the energy criterion of similarity with consideration to the scale, the volume concentration of energy of the explosive used in production (Granemit 50/50) was determined, but since the critical diameter of Granemit exceeds the diameter of the borehole on the physical model, the ten is used as the explosive. By changing the density of the ten, we bring the volume concentration to a value equal to $5152 \mathrm{MJ} / \mathrm{m}^{3}$. For a charge equal to Granemit 50/50, it is:

$$
\Delta=E_{1} / Q_{2}=5152 / 5,86=880 \mathrm{~kg} / \mathrm{m}^{3}
$$

where $\Delta$ - charge density, $\mathrm{kg} / \mathrm{m}^{3} ; \mathrm{Q}$ - explosion heat, $\mathrm{MJ} / \mathrm{kg} ; \mathrm{E}$ - energy volume concentration, $\mathrm{MJ} / \mathrm{m}^{3}$.

Thus, in the monolithic ferrous quartzite slab, a $4 \mathrm{~mm}$ diameter borehole was drilled (Fig.1), in which the charge of the ten with a density of $0.88 \mathrm{~g} / \mathrm{cm}^{3}$ was placed. To initiate the charge, an electric igniter was injected into the mouth of the channel. 


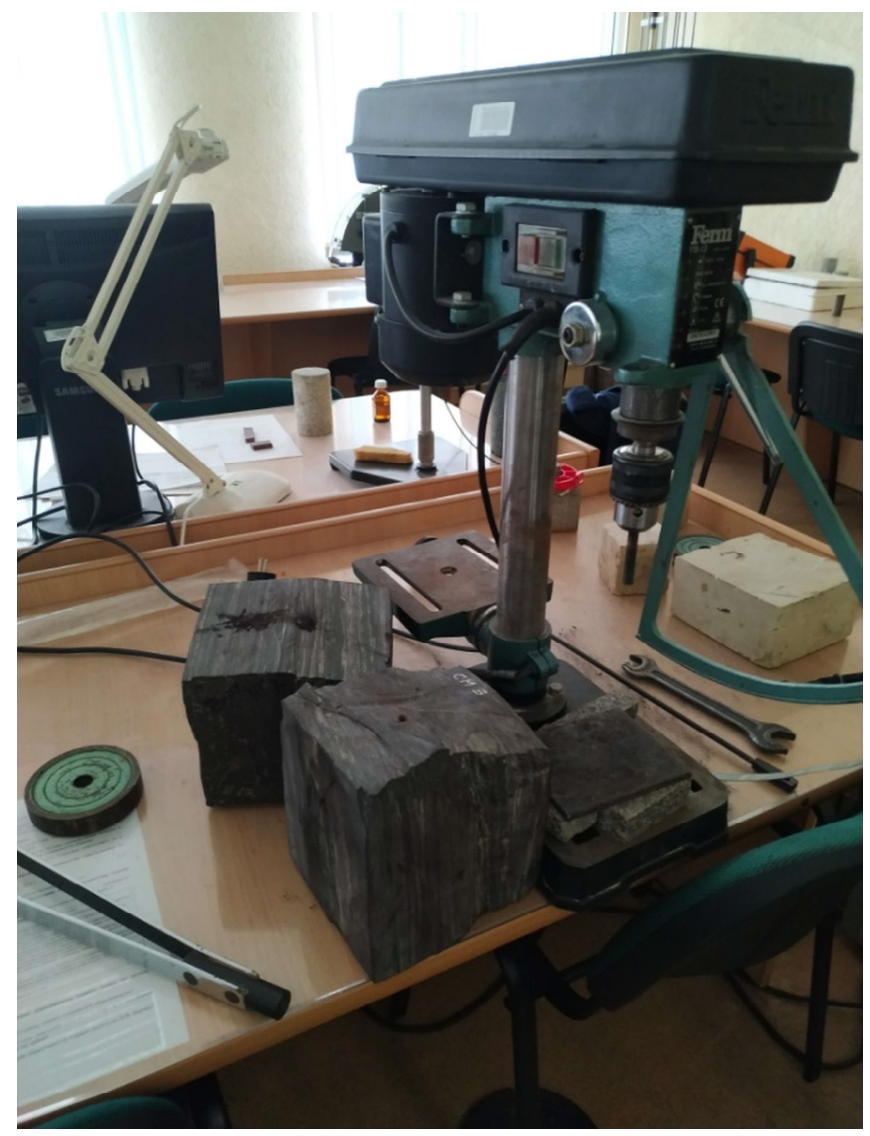

Fig. 1. Formation of the charge cavity in the slab.

The next action was to place the accelerometer sensors on the physical models, the measurements were made with the Tetronix digital oscilloscope [4]. The accelerometers were dynamically calibrated before using them for measurements under experimental conditions.

Following the laboratory experiment, the model of borehole charge blasting in a threedimensional setting in the Autodyn software system was developed [5]. The model geometry was made according to the linear parameters of the slab which was used for the laboratory experiment. To determine the behavior of an explosive and detonation products used in the engineering calculation, an equation of state is required, which defines the relationship between the state parameters of the explosive. The Jones-Wilkins-Lee (JWL) equation of state was used for numerical modeling because it can accurately describe the behavior of different explosives. To describe the behavior of the ten with a density of 0.88 $\mathrm{g} / \mathrm{cm} 3$, it is necessary to set constants for the JWL equation of state. Using the method proposed in paper [6], based on the available database for PETN with four different densities, constants were extracted from the standard AUTODYN library to study the applicable correlations.

The general rock material model requires equations that relate stress to strain and internal energy (or temperature). In most cases, the stress tensor can be divided into a homogeneous hydrostatic pressure (all three normal stresses are equal) and a stress deviator tensor associated with the shear strain material resistance. The polynomial equation describing the rock behavior was chosen as the equation of state. Rock strength is described 
with the JH-2 strength model. Based on its original concept presented in [7], the JH-2 model adds softening parameters. An overview of the model is presented in the sources $[8,9,10]$. The main parameters of the explosives used are given in Table 2, and for rock, the values given in Table 1 are used.

Table 2. Parameters of the ten used in the calculation.

\begin{tabular}{|c|c|}
\hline Parameter & Value \\
\hline Density, $\mathrm{kg} / \mathrm{m}^{3}$ & 880 \\
\hline Detonation velocity, $\mathrm{m} / \mathrm{s}$ & 5170 \\
\hline Energy volume concentration, $\mathrm{MJ} / \mathrm{m}^{3}$ & $5,15 \cdot 10^{3}$ \\
\hline Shock front pressure, $\mathrm{GPa}$ & 6,2 \\
\hline
\end{tabular}

\section{Results and Discussion}

As a result of experimental blasts, oscillograms were obtained, which represent the dependence of radial acceleration of the ore body on time. The values of displacement velocities (Table 2) were determined by integrating the accelerogram over time. Also, the results of slab crushing (Fig.2) in the form of particle size distribution using the photoplanimetric method were taken [12].

Table 3. Results of determination of displacement velocity values for the slab No. 1.

\begin{tabular}{|c|c|c|}
\hline Sensor number & $\begin{array}{c}\text { Distance from charge to sensor } \\
\text { location, } \mathrm{mm}\end{array}$ & $\begin{array}{c}\text { Maximum drift } \\
\text { velocity, } \mathrm{m} / \mathrm{s}\end{array}$ \\
\hline 2 & 53 & 1,8 \\
\hline 1 & 62 & 2,6 \\
\hline 3 & 49 & 2,1 \\
\hline 4 & 65 & 2,9 \\
\hline
\end{tabular}

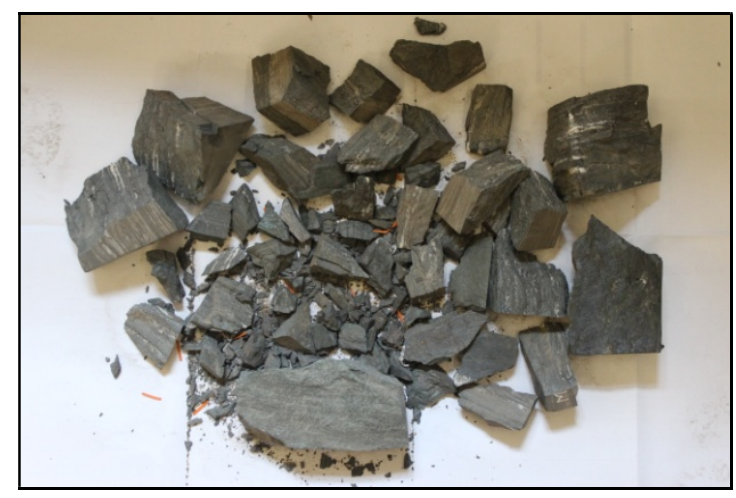

Fig. 2. The result of explosive loading of a ferrous quartzite slab

To obtain the same data, the numerical model was provided with the typical sensors. Their location is exactly the same as that of the accelerometers on the physical model. Thus, we can objectively compare the results obtained (Fig. 3). 
Gauge History ( Ident 0 - admodel)
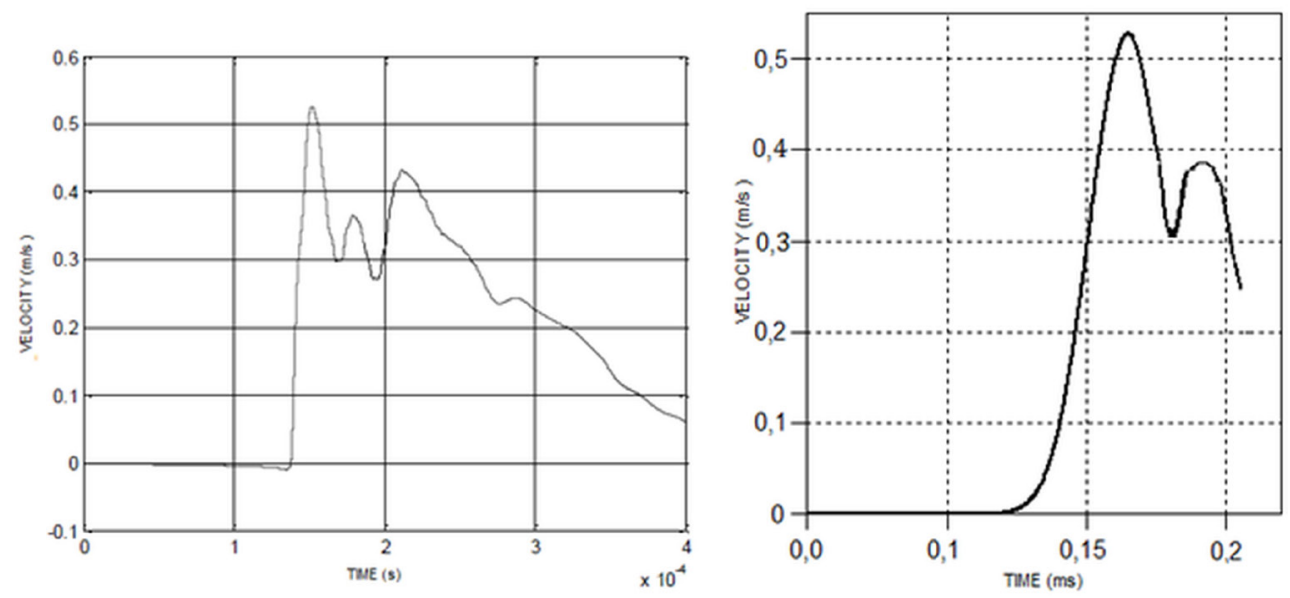

Fig. 3. The velocigrams received from the model block and from the sensor on the numerical model.

Examples of the stage of numerical calculation of the blast action are shown in Figures 4,5 . The color shows the zones of equivalent stress and the passage of the detonation front through the explosive. When modeling, the full stress tensor is calculated in the rock mass during the borehole charge blast. The stress state is evaluated using the equivalent von Mises stress, considering all three main components of the stress tensor. The stages of the shockwave through the rock are shown in Figure 5.

$$
\sigma_{\ni}=\sqrt{\frac{\left(\sigma_{1}-\sigma_{2}\right)^{2}+\left(\sigma_{2}-\sigma_{3}\right)^{2}+\left(\sigma_{3}-\sigma_{1}\right)^{2}}{2}}, P a
$$

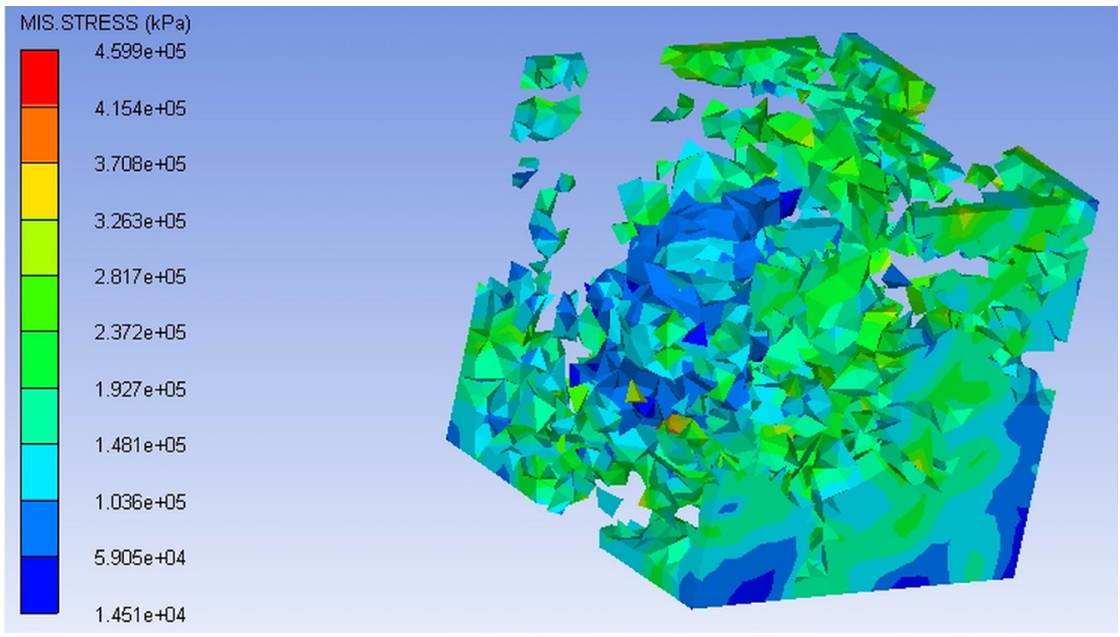

Fig. 4. Field of equivalent stresses on a fragmented model. 


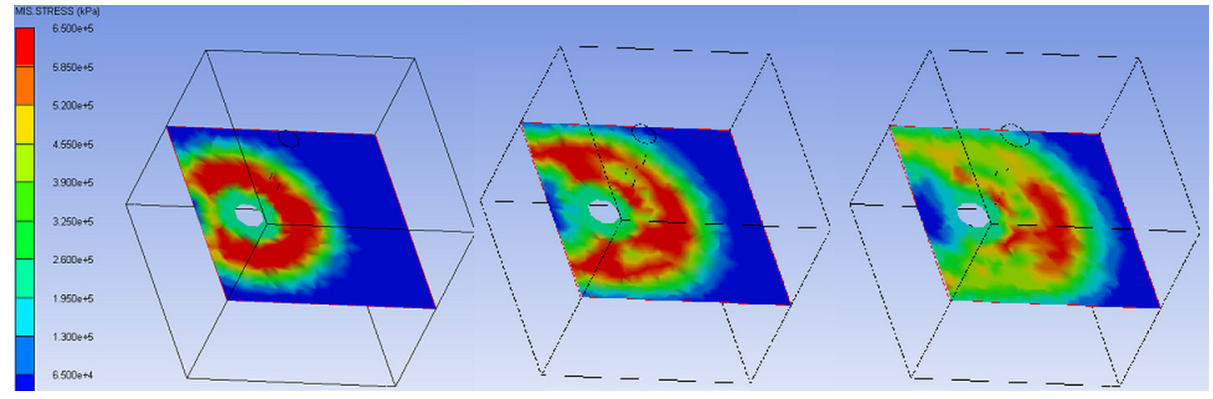

Fig. 5. Shockwave propagation across the block.

\section{Conclusions}

Analyzing the results, it is possible to note sufficient convergence of the results of the laboratory and numerical experiment, which allows using the calibrated model for the study of borehole charges of various designs for the conditions of the Mikhailovskoye iron ore deposit.

Thus, this paper presents a systematic approach to conducting computational experiments using the Ansys software system. It is found that when modeling a blast in ferrous quartzites, the Johnson-Holmquist-II damage model is sufficient to obtain adequate real results. The paper shows the possibility of determining the zone of the most probable rock mass disturbance in case of a blast, as well as the distribution of fields of values of interest.

Based on the verified model, it is possible to perform numerical calculations of the blast action of borehole charges of various designs, such as those dispersed by air or inert gaps, to improve the efficiency of drilling and blasting operations in the quarry. The proposed approach can be used to identify the features of rock mass destruction by a system of borehole charges at different deceleration intervals between them

\section{References}

1. R. I. Sukhov, A. S. Regotunov, Bulletin of Scientific, Technical and Economic Information, Ferrous Metallurgy, 10, 22 (2017)

2. G. P. Paramonov, IOP Conf. Ser.: Earth Environ. Sci., 194, 082031(2018)

3. B. R. Rakishev, Automated design and production of mass explosions in quarries (Gylym, Almaty, 2016)

4. F. A. Baum, The physics of explosions (Nauka, Moscow, 1975)

5. TDS2000C Series Oscilloscope Manual (Tektronix Inc, Beaverton, 2006)

6. Autodyn. Theory manual (Ansys inc., Houston, 2005)

7. D. M. M. Badanaki, Phd Thesis, University of Toronto, 77 (2010)

8. G. R. Johnson, T. J. Holmquist, Shock Wave and High-Strain-Rate Phenomena in Material (CRC Press: Boca Raton, 1992)

9. G. R. Johnson, T. J. Holmquist. AIP Conf of High-Pressure Science and Tech, 309, 981-984 (1993)

10. G. R. Johnson, T. J. Holmquist, J. Appl. Phys.,85, 8060-8073 (1996) 
11. G. R. Johnson, T. J. Holmquist, J. Appl. Phys., 95, 1639-1646 (1997)

12. J. Wang, Y. Yin, C. Luo, Appl. Sci., 8, 1675 (2018)

13. WipFrag 3 Manual (AMS, Sidney, 2019) 